\title{
Study on clinical and hematological profile of Anemia in children aged 5 to 12 years in rural Telangana
}

\author{
Ramana Sastry C.P.V ${ }^{1}$ \\ ${ }^{1}$ Dr. CPV Ramana Sastry, Associate Professor, Department of Pediatrics, Maheshwara Medical College and \\ Hospital, Patancheru, Telangana, India.
}

Address for Correspondence: Dr.CPV Ramana Sastry, Associate Professor, Department of Pediatrics, Maheshwara Medical College and Hospital, Patancheru, Telangana. E-mail ID: docmic175@gmail.com

\begin{abstract}
Introduction: Anemia is a major global health problem, especially in developing countries like India, despite the fact that this problem is largely preventable \& easily treatable. Aim: The aim is to study the clinical and hematological profile of anemia in children aged 5 years to 12 years. Material and Methods: It is a prospective hospital based study conducted in children presented with anemia in the department of Pediatrics at Maheshwara Medical College and Hospital, Patancheru, Telangana. 110 pediatric cases of anemia were included in the study. Results: Majority of children were among followed by 5- 6 years. Among different types of anemia studied, iron deficiency was reported predominantly $80 / 110$ (72.7\%) followed by megaloblastic anemia 20/110 (18.1\%). There was female preponderance. Microcytic hypochromic anemia is seen in $81.8 \%(90 / 110)$. Dimorphic anemia was observed in $9.09 \%$ of children. Conclusion Nutritional deficiency anemia is the most common cause of anemia among children aged 5 years to 12 years. Iron deficiency was found to be most common nutritional deficiency in children followed by megaloblastic anemia.
\end{abstract}

Key words: Anemia, Iron deficiency, Microcytic anemia, Nutritional anemia

\section{Introduction}

Anemia is a major global health problem, especially in developing countries like India, despite the fact that this problem is largely preventable $\&$ easily treatable.

It is the commonest disease affecting humankind and is responsible for morbidity and mortality among general population. About $30 \%$ or nearly one third of world's population is suffering from anemia due to various causes $[1-4]$.

Anemia can be of various types, but most common in developing countries is nutritional anemia. Nutritional anemia can be due to Iron deficiency (most common cause), Folic acid deficiency, Vitamin B12 deficiency or may be combination of these factors, which can present with dimorphic picture.

These conditions are seen in all types of medical practice ranging from neonatology to geriatrics and public health and are an ongoing concern to all physicians. Other types include hemolytic anemia, which can be either congenital or acquired.

Congenital causes include membrane defect, hemoglobin defects and enzyme defect while acquired causes can be immune or non- immune. Aplastic anemia, anemia due to blood loss and anemia of chronic disease are the some other types of anemia [5].

Manuscript received: $6^{\text {th }}$ July 2017

Reviewed: $15^{\text {th }}$ July 2017

Author Corrected: $24^{\text {th }}$ July 2017

Accepted for Publication: $31^{\text {st }}$ July 2017 
Original Research Article

Table-1: Criteria used for diagnosing anemia:-WHO Criteria for Anemia and Grade of severity [6]

\begin{tabular}{|c|c|c|c|c|c|}
\hline & Population & Non-Anemia & \multicolumn{3}{|c|}{ Anemia (Gm/dL) } \\
\cline { 4 - 6 } & & $(\mathbf{G m} / \mathbf{d L})$ & Mild & Moderate & Severe \\
\hline 1. & Children 6-59 months of age & 11 & $10.0-10.9$ & $7.0-9.9$ & $<7.0$ \\
\hline 2. & Children 5-11 years of age & 11.5 & $11.0-11.4$ & $8.0-10.9$ & $<8.0$ \\
\hline 3. & Children 12-14 years of age & 12 & $11.0-11.9$ & $8.0-10.9$ & $<8.0$ \\
\hline 4. & Non-pregnant women & 12 & $11.0-11.9$ & $8.0-10.9$ & $<8.0$ \\
\hline 5. & (15 years of age and above) & & & & $<7.0$ \\
\hline 6. & Pregnant women & 11 & $10.0-10.9$ & & $<8.9$ \\
\hline
\end{tabular}

Iron deficiency is the most common and widespread nutritional disorder in the world [7]. It is the only nutrient deficiency which is also significantly prevalent in all industrialized nations. According to the data of the World Health Organization (WHO), the prevalence of iron deficiency anemia (IDA) in industrialized countries and in non-industrialized countries is $10-20 \%$ and $50-60 \%$, respectively [8].

Iron deficiency impairs the cognitive development of children from infancy through adolescence. It also damages immune mechanisms and is associated with increased morbidity rates. The importance of iron deficiency and anaemia as a public health problem has been increasingly recognized by health authorities and policy makers. Although efforts are targeted primarily to prevent iron deficiency, it is still the most common nutrient deficiency all over the world [8]. About half of the population in the developing countries has iron deficiency anaemia. Preschool, school and adolescent children and women in childbearing age are at increased risk. Iron deficiency anaemia affects $30 \%$ of the world population $[9,10]$.

\section{Aim}

The main objective is to study the clinical and hematological profile of anemia in children aged 5 years to 12 years.

\section{Materials \& Methods}

This prospective study was conducted at Maheshwara medical college and hospital, Patancheru, Telangana, for duration of 1 year between May 2016 - April 2017 after obtaining Ethical committee clearance. The children aged 5 years to 14 years who were admitted in pediatric ward with history of severe pallor were selected randomly and included irrespective of sex, and duration of disease. An Informed consent was taken from parents of all children who were included in the study. A detailed history was recorded with particular emphasis on symptoms suggestive of anemia such as weakness and easy fatigability, breathlessness on exertion, pica. A thorough clinical examination of every child was done especially for pallor, nail changes, glossitis, fundus of eye, cardio vascular involvement in form of tachycardia, haemic murmur, congestive cardiac failure, raised JVP and edema.

Routine Investigations for anemia and its causes was done. i.e. Hb estimation, complete hemogram, peripheral smear, Reticulocyte count, serum vitamin B12, serum folic acid, stool for worm infestation were done in all patients. Hemoglobin was estimated by Sahli's method and expressed in gm\%, peripheral smear was stained by Leishman's stain. Anemia was classified morphologically based on peripheral smear findings. PCV, MCV, MCH, MCHC and RDW were determined by automated cell counter. Normal values were taken as follows: PCV 3545\%, MCV 77-95fl, MCH 25-33pg, MCHC 31-37gm/dl and RDW 14.5-18.5.

Reticulocyte count was done by Brilliant crystal stain method, serum iron determination was done by Ramany's dipyridyl method, Total iron binding capacity was determined by Ramsay's method, serum vitamin B12 and folic acid was determined by Architect method. 
Inclusion criteria: Patients with anemia in age group of 5 years to 14 years admitted in pediatric ward.

Exclusion criteria: children less than 2 years and teenagers more than 14 years. out patients who were not admitted in the hospital. Patients having mild to moderate anemia, severe anemia due to malaria, and patients collapsed due to congestive cardiac failure within 12 hours of admission, communicable diseases like HIV, tuberculosis \& hepatitis were excluded.

Statistical Analysis- Data were entered in Microsoft Excel 2007 and all statistical analyses were performed. SPSS for Windows version 17.0, Chicago, USA, was also used for data analysis. Descriptive characteristics (mean and standard deviation) and percentage were performed for each parameter separately. Chi-square and independent $t$ test were used for proportions and mean comparisons between groups, respectively. Pearson's correlation tests were performed to examine the relationships between hematological indicators.

\section{Results}

A total of 110 cases aged between 4- 12 years were included in the study. The most common affected age- group was $7-8$ years $(54.5 \%)$ ( Table 2$)$

Table-2: Age-wise distribution of cases.

\begin{tabular}{|c|c|c|}
\hline Age in years & No. of cases & \% \\
\hline $5-6$ years & 30 & 27.3 \\
\hline $7-8$ years & 60 & 54.5 \\
\hline 9-10 years & 10 & 9.09 \\
\hline 11-12 years & 10 & 9.09 \\
\hline Total & $\mathbf{1 1 0}$ & $\mathbf{1 0 0}$ \\
\hline
\end{tabular}

There was female preponderance in this study. (63.6\% compared to males (36.3\%). Weakness \& fatigability were the most common presenting symptom observed in $81.8 \%$ of children. On General examination Pallor was seen in $100 \%$ of patients, knuckle pigmentation in $18.1 \%$, and koilonychia in $36.3 \%$. (Table 3 )

Table-3: Clinical signs and symptoms.

\begin{tabular}{|c|c|c|}
\hline Clinical signs and symptoms & No. of cases & \% \\
\hline Pallor & 110 & $27.2 \%$ \\
\hline Icterus & 30 & $40.9 \%$ \\
\hline Fever & 45 & $27.2 \%$ \\
\hline Cough & 30 & $18.1 \%$ \\
\hline Hyperpigmentation & 20 & $81.8 \%$ \\
\hline Weakness and fatigability & 90 & $18.1 \%$ \\
\hline Splenomegaly & 20 & $18.1 \%$ \\
\hline Tremors & 20 & $27.2 \%$ \\
\hline Hepatomegaly & 30 & $9.09 \%$ \\
\hline petechiae & 10 & $27.2 \%$ \\
\hline Vomitings & 30 & $18.1 \%$ \\
\hline Shortness of breath & 20 & $27.2 \%$ \\
\hline History of Pica & 30 & $36.3 \%$ \\
\hline koilonychia & 40 & \\
\hline
\end{tabular}

About 60 (54.5\%) children had severe anemia. 30(27.2\%) moderate anemia and 20 (18.1\%) mild anemia. (table 4) 
Table-4: Severity of anemia (according to $\mathrm{Hb} \%$ )

\begin{tabular}{|c|c|c|c|c|}
\hline Grade of Anemia & Males & Females & Total & \% \\
\hline Mild & 10 & 10 & 20 & 18.1 \\
\hline Moderate & 10 & 20 & 30 & 27.2 \\
\hline Severe & 20 & 40 & 60 & 54.7 \\
\hline Total & $\mathbf{4 0}$ & $\mathbf{7 0}$ & $\mathbf{1 1 0}$ & $\mathbf{1 0 0}$ \\
\hline
\end{tabular}

Peripheral smear examination: Microcytic hypochromic anemia is seen in $81.8 \%(90 / 110)$. Dimorphic anemia is seen in $9.09 \%$. Normocytic Normochromic anemia is seen in $9.09 \%$ of patients.

Among different types of nutritional anemia studied, iron deificiency was reported predominantly 80/110 (72.7\%) followed by megaloblastic anemia 20/110 (18.1\%). Least were aplastic anemia and hemolytic anemia 5 cases each (4.5\%). incidence of iron deficiency anaemia is more in females i.e., 60(75\%) compared to males $20(25 \%)$ while for megaloblastic anemia incidence was more in males i.e., $15(75 \%)$ compared to $5(25 \%)$ females.

Table-5: Showing relation of $\mathrm{RBC}$ indices in anemia.

\begin{tabular}{|c|c|c|}
\hline Relation of RBC indices in anemia. & Iron deficiency anemia & Megaloblastic anemia \\
\hline $\mathrm{PCV} \downarrow$ & $80(72.7 \%)$ & $20(18.1 \%)$ \\
\hline $\mathrm{MCV} \downarrow$ & $80(72.7 \%)$ & - \\
\hline $\mathrm{MCV} \uparrow$ & - & $20(18.1 \%)$ \\
\hline $\mathrm{MCH} \downarrow$ & $80(72.7 \%)$ & - \\
\hline $\mathrm{MCH} \uparrow$ & - & $20(18.1 \%)$ \\
\hline $\mathrm{MCHC} \downarrow$ & $80(72.7 \%)$ & $20(18.1 \%)$ \\
\hline $\mathrm{MCHC}$ normal & - & $20(18.1 \%)$ \\
\hline $\mathrm{RDW} \uparrow$ & $80(72.7 \%)$ & - \\
\hline $\mathrm{RDW} \downarrow$ & - & $20(18.1 \%)$ \\
\hline
\end{tabular}

Note: PCV: packed cell volume; MCV: mean corpuscular volume; $\mathrm{MCH}$ : mean corpuscular hemoglobin; $\mathrm{MCHC}$ : mean corpuscular hemoglobin concentration; RDW: red cell distribution width.

In Iron deficiency anemia PCV, MCV, MCHC, $\mathrm{MCH}$ are decreased and $\mathrm{RDW}$ is increased.

In megaloblastic anemia PCV decreased, $\mathrm{MCV}$ and $\mathrm{MCH}$ are increased, and $\mathrm{MCHH}$ are normal.

$18.1 \%$ patients having serum level $<30 \mu \mathrm{g} / \mathrm{dl}$ while $72.7 \%$ patients having serum Iron level between $30-60 \mu \mathrm{g} / \mathrm{dl}$.

\section{Discussion}

The term 'nutritional anemia' encompasses all pathological conditions in which the blood hemoglobin concentration drops to an abnormally low level, due to a deficiency in one or several nutrients. The main nutrients involved in the synthesis of hemoglobin are iron, folic acid, and vitamin B. Iron deficiency is by far the first cause of nutritional anemia worldwide. Folic acid deficiency is less wide-spread and is often observed with iron deficiency. Vitamin B deficiency is far rarer.

About 110 patients of anemia between the age group of 5 years to 12 years have been studied. $54.2 \%$ of them were in the age-group 7-8 years old. Venkatesh $\mathrm{G}$ et al study included 9124 patients of which anemia was found in 7412(81.2\%) and severe anemia in 202 patients, prevalence of severe anemia being 2.2\% [11]. Divya Regina, et al study included total of 1007 subjects belonging to 6-11 years. The maximum numbers were 9 years old (22\%) [12]

Female preponderance was observed in this study (males 40/110 (36.3\%). Srinivas Other authors have also observed similar findings in their study $[12,13,14]$. While Gupta $\mathrm{S}$ et al showed male preponderance [15].

The most common cause of anemia in this study was iron deficiency $(58 \%)$ while sickle cell disorders $27 \%, 9 \%$ were thalasemic and $5 \%$ cases had 
megaloblastic anemia and $2 \%$ Aplastic anemia were less common causes. Srinivas Madoori et al was found that of 58\% (183) children were anemic due to iron deficiency anemia while $9 \%$ (29) were thalasemic and $27 \%(85)$ were sickle cell disorder [13]. 5\% (16) cases had megaloblastic anemia and $2 \%$ (6) with aplastic anemia. Venkatesh G, et al reported iron deficiency anemia the most common followed by dimorphic anemia and megaloblastic anemia [11].

The prevalence of iron deficiency anemia was more in females i.e., 60(75\%) than males $20(25 \%)$. while megaloblastic anemia was prevalent in males i.e., $15(75 \%)$ compared to females (25\%). Venkatesh G, et al observed similar findings in their study [11].

Peripheral smear examination showed Microcytic hypochromic anemia in $81.8 \%$ (90/110). Dimorphic anemia was seen in $9.09 \%$. Normocytic Normochromic anemia is seen in $9.09 \%$ of patients.

In Venkatesh $\mathrm{G}$ observed Microcytic hypochromic anemia in $54.4 \%$, macrocytic hypochromic anemia is seen in $11.8 \%$ and dimorphic anemia is seen in $36.6 \%$ of patients [11].

In Iron deficiency anemia PCV, MCV, MCHC, $\mathrm{MCH}$ are decreased and RDW is increased.

Under iron deficiency condition, formation of $\mathrm{Hb}$ is reduced resulting in a reduction of $\mathrm{MCH}$ [16]. The transmembrane protein (ferroportin) is responsible for the transfer of iron from enterocytes and monocytes/macrophages to the circulation. It was found that ferroportin mRNA expression was significantly reduced in monocytes of anemic subjects compared with controls [17].

Importantly, the decreased expression of ferroportin was paralleled by increased iron storage in monocytes of anemia of chronic disease patients as estimated by hyperferritinemia. As a functional consequence of decreased ferroportin expression and the subsequent reduction of cellular iron export, intracellular iron levels will increase which interferes in the process of erythropoiesis, thus decreasing expression of monocytes leading to decrease in $\mathrm{Hb}$. In this study, inverse relationship of RDW was seen with the $\mathrm{Hb}$ in iron deficiency anemia; however, no such correlation happened with non iron deficiency anemia [18].
There is a strong association between $\mathrm{MCV}$ and $\mathrm{MCH}$ in iron deficiency and megaloblastic conditions [19]. It was observed that association between high MCV (above cut-off) and high $\mathrm{MCH}$ (above cut off) as well as a higher peripheral blood monocyte count with venous thrombosis indicates association of these blood indices in vivo [20].

\section{Conclusion}

In the present study Nutritional deficiency anemia is the most common cause of anemia among children aged 5 years to 12 years. Iron deficiency was found to be most common nutritional deficiency in children followed by megaloblastic anemia.

We recommend awareness creation on water and sanitation and nutritional counseling to parents on consumption of iron-rich foods and iron supplementation to prevent anemia among young children with special emphasis on those from low income group and socioeconomic deprived communities.

Funding: Nil, Conflict of interest: None initiated, Perission from IRB: Yes

\section{References}

1. McLean E, Cogswell M, Egli I, Wojdyla D, de Benoist B. Worldwide prevalence of anaemia, WHO Vitamin and Mineral Nutrition Information System, 1993-2005. Public Health Nutr. 2009 Apr;12 (4):444-54.doi:10.1017/S136898000800 2401. Epub 2008 May 23.

2. Maurício S Leite, Andrey M Cardoso, Carlos EA Coimbra, James R Welch, Silvia A Gugelmin, Pedro Cabral I Lira, Bernardo L Horta, Ricardo Ventura Santos and Ana Lúcia Escobar. Prevalence of anemia and associated factors among indigenous children in Brazil: results from the First National Survey of Indigenous.People's Health and Nutrition. Nutrition Journal 2013;12:69.

3. Milman N. Anemia--still a major health problem in many parts of the world! Ann Hematol. 2011 Apr; 90 (4):369-77. doi: 10.1007/s00277-010-1144-5. Epub 2011 Jan 8.

4. Khambalia AZ, Aimone AM, Zlotkin SH. Burden of anemia among indigenous populations. Nutr Rev. 2011 Dec; 69(12):693-719. doi: 10.1111/j.17534887. 2011.00437.x. 
5. Tolentino K, Friedman JF. An update on anemia in less developed countries. Am J Trop Med Hyg. 2007 Jul;77(1):44-51.

6. Panigrahi A, Sahoo PB. Nutritional anemia and its epidemiological correlates among women of reproductive age in an urban slum of Bhubaneswar, Orissa. Indian J Public Health.2011;55:317-20. [PubMed)

7. DeMaeyer E, Adiels-Tegman M. The prevalence of anaemia in the world. World Health Stat Q. 1985;38(3):302-16.

8. World Health Organisation, Iron Deficiency Anaemia Assessment, Prevention, and Control, A Guide for Programme Managers, WHO, 2001.

9. Shally Awasthi, Rohini Das, Tuhina Verma, Sheila Vir. Anemia and Undernutrition Among Preschool Children in Uttar Pradesh, India. Indian Pediatrics, 2003; 40:985-990.

10. Sarah E Cusick, Zuguo Mei, David S Freedman, Anne C Looker, Cynthia L Ogden, Elaine Gunter,et al. Unexplained decline in the prevalence of anemia among US children and women between 1988-1994 and 1999-20021-3. The American Journal of Clinical Nutrition, 2008;88: 1611-7.

11. Venkatesh G1, Soubhagya Talawar2, Bela H Shah3, Clinical Profile of Anemia in Children. IOSR Journal of Dental and Medical Sciences 2013;10(5):65-69.

12. Divya Regina, Sudharshan Raj C, Raghav Rao ,Correlation of pallor with hemoglobin levels and clinical profile of anemia in primary and middle school children of rural Telangana. Int J Contemp Pediatr. 2016 Aug; 3(3):872-877.
13. Srinivas Madoori, Ramya C., Shashidhar Valugula, Sandeep G., Sreenivas Kotla Clinico hematological profile and outcome of anemia in children at tertiary care hospital, Karimnagar, Telangana, India. Int J Res Med Sci. 2015 Dec; 3 (12): $3567-3571$

14. Jain N, Jain VM. Prevalence of anemia in school children. Indian Medical Practice and Review. 2012; $3(1): 1-4$

15. Gupta S. Silent burden of anemia in school age children: A community based study in West Bengal. Indian journal of medical sciences. 2012;66(7):163.

16. B. Thompson. Food-based approaches for combating iron deficiency. In Nutritional Anemia, M. B. Zimmermann and K. Kraemer, Eds., SIGHT and LIFE Press, Basel, Switzerland, 2007; pp. 338-358,

17. I. Theurl, V. Mattle, M. Seifert, M. Mariani, C. Marth, and G. Weiss. Dysregulated monocyte iron homeostasis and erythropoietin formation in patients with anemia of chronic disease. Blood, 2006; 107 (10): 4142-4148.

18. R. Aulakh, I. Sohi, T. Singh, and N. Kakkar. Red cell distribution width (RDW) in the diagnosis of iron deficiency with microcytic hypochromic anemia. Indian Journal of Pediatrics, 2009; 76 (3): 265-267.

19. R.F. Croft, A.M. Streeter B.J.O'neill. Redcellindicesin megaloblastosis and iron deficiency, Pathology, 1974; 6 (2):107-117.

20. S.M. Rezende, W.M. Lijfering, F.R. Rosendaal and S.C. Cannegieter. Hematologic variables and venous thrombosis:red cell distribution width and blood monocyte count are associated with an increased risk. Haematologica, 2014;99(1):194-200.

\section{How to cite this article?}

Ramana Sastry C.P.V. Study on clinical and hematological profile of Anemia in children aged 5 t0 12 years in rural Telangana. J PediatrRes.2017;4(07):488-493.doi:10.17511/ijpr.2017.i07.09. 